\title{
Out of joint: The story of the ASR
}

Why did it take so long to recall from the market a hip implant after it became apparent that it was causing pain and disability in patients. In an investigation for the BMJ, Deborah Cohen describes how companies dictate the fate of their own devices and exert an unduly strong hold over surgeons

\section{Deborah Cohen investigations editor}

BMJ, London WC1H 9JR, UK
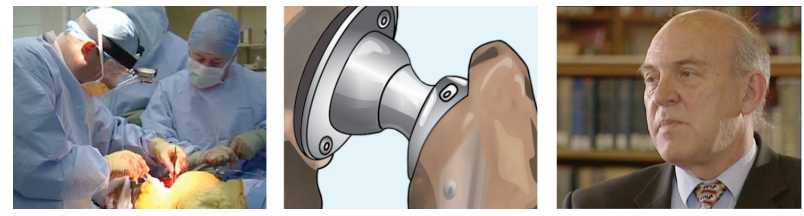

It is one of the biggest disasters in orthopaedic history, according to one senior surgeon. On 24 August 2010, DePuy, a subsidiary of American giant Johnson and Johnson, recalled its ASR (articular surface replacement) hip prostheses from the market. The recall followed years of denial by the company that the ASR implants had caused pain and disability in patients. In a statement to the $B M J$, DePuy claim that "given the available information, we believe we made the appropriate decision to recall at the appropriate time."

Pathologically, the failing prosthesis had several effects. Metal debris from wear of the implant led to a reaction that destroyed the soft tissues surrounding the joint, leaving some patients with long term disability. Ions of cobalt and chromium-the metals from which the implant was made-were also released into the blood and cerebral spinal fluid in some patients. ${ }^{1}$

The long term effects are uncertain. But the US Food and Drug Administration recommends that patients should be monitored for systemic effects, particularly cardiovascular, neurological, renal, and thyroid signs and symptoms. ${ }^{1}$

With more than 93000 ASR implants sold and ongoing litigation in many countries, the situation may prove costly for DePuy. And if lessons are not learnt from this latest episode in the chequered history of hip implant failures, it may also prove costly for the reputations of the regulators and the orthopaedic community.

The ASR is not the first hip implant to be recalled - there have been many others. One such recall in the late 1990s-the 3M Capital Hip—prompted questions about European device regulation $^{2}$ and a parliamentary investigation by then health minister, Lord Hunt. ${ }^{3}$ But nor may it be the last-concerns are now being raised about the failure rates of other metal on metal hip implants. ${ }^{4}$

\section{Metal on metal}

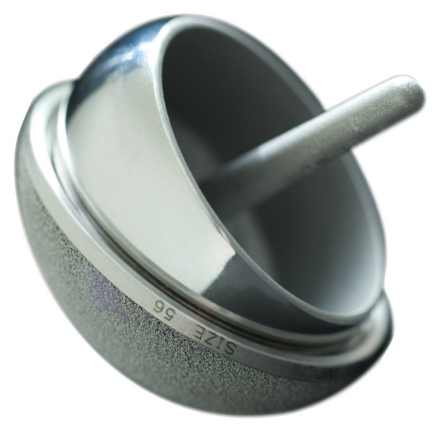

The ASR is a "metal on metal" hip- the head at the top and the lining of the cup it fits into are made of cobalt chrome metal rather than ceramic or polyethylene. The devices come in different sizes according to the existing anatomy and there are forms for both total hip replacement (ASR XL) and hip resurfacing (ASR resurfacing).

The conventional total hip replacement consists of a metal head with a polyethylene cup. But these joints don't last forever. Over time the plastic cup wears away against the hard metal head. Younger, more active people are especially likely to require early revision surgery to replace the worn out joint. ${ }^{5}$ 


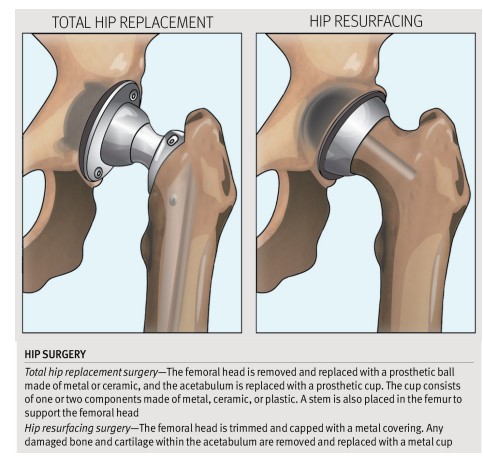

In search of a more durable option, surgeons turned their attention to the development of joints using a metal head against a metal cup. Not only would metal be much harder wearing, but advancements in manufacturing meant that the metal could be produced with incredibly smooth surfaces. Complicated physical phenomena dictate that these smooth bearing surfaces trap a layer of fluid between them. So in perfect circumstances, the metal surfaces do not touch and the surfaces wear very little. And, in theory, the quicker the patient moves the thicker this fluid layer becomes, ensuring even less wear. ${ }^{67}$

Competition between manufacturers spurred DePuy to develop the ASR. A new hip prosthesis called the Birmingham Hip Resurfacing (BHR), designed by UK surgeon Derek McMinn, had entered the European market in 1997 (the FDA approved it in 2006), and was proving popular. Smith and Nephew acquired it, and DePuy had to design a better product so that it didn't lose market share. The attempt to prise surgeons away from the BHR led to fractious competition between the companies, which was reflected in their marketing campaigns.

\section{Simulator testing}

Both forms of the DePuy ASR came on to the market in Europe in 2003. At the time, resurfacing prostheses were classed as a class IIb device, which meant they didn't need to be tested in patients before entering the EU market.

DePuy followed and met the European standards. These provide guidance on how to conduct simulator studies to test how well the implant wears. According to DePuy, it conducted laboratory testing "including tests on simulators that evaluate how the device wears over time, the materials used in the device and device strength."

But exactly what information the company submitted is not open to public scrutiny - the scientific rationale is held by the company and by the notified body-one of several private organisations that do the premarket approval on behalf of EU governments. ${ }^{8}$ In this case the notified body was the British company BSI. ${ }^{9}$

The UK Medicines and Healthcare Products Regulatory Agency (MHRA) says that clinical studies may be too small and short to detect problems for premarket approval purposes. But clinical tests with relatively short follow-up may have picked up problems with the ASR. According to David Langton, a surgical researcher at the University Hospital of North Tees and Newcastle University who has been studying the ASR, problems in some patients first emerged about two years after implantation. ${ }^{10}$

The absence of any clinical studies of implants in patients before approval remains a cause for concern-much like it was over 10 years ago with the $3 \mathrm{M}$ Capital hip. ${ }^{2}$

"The reason they get on to the market is that they look and smell like a joint replacement," says Stephen Graves, orthopaedic surgeon and director of the Australian National Joint Replacement Registry. Professor Graves thinks that simulator testing should not be relied on entirely to see if a device will function well when you use it in a person. Indeed, a recent Smith and Nephew backed paper suggests that simulators do not really represent the biological environment. ${ }^{11}$

"Before a hip or knee replacement is placed onto the market it should have been used in a limited number of people who had been monitored very carefully for a number of years," Professor Graves says, adding "the outcome of that monitoring would indicate that the device is actually working very satisfactorily in that small group of patients."

Professor Graves thinks this would not only protect patients but also the company. "They [clinical studies] may well prevent a situation where they have a device that is not performing anywhere near as well as they would have hoped," he says.

\section{Problems emerge}

Although the ASR resurfacing made it onto the European market, it was not approved in the US. Resurfacing was a new technique and so the implant had to go through the FDA's more rigorous premarket approval process. This requires manufacturers to submit their product to clinical testing to prove it is both safe and - unlike the European process-effective for its intended use. The FDA asked DePuy to perform a clinical study called an investigational device exemption (IDE).

Tony Nargol, an orthopaedic surgeon at the University Hospital of North Tees, was one of the surgeons involved in the studies for the American market. But not everything was going to plan. As internal DePuy emails show, he reported problems with fractures in some of his patients. The FDA sent detailed questions to the company.

"You have not provided any explanation why this experienced investigator may have had a higher femoral neck fracture rate in this IDE study. It is concerning that an experienced surgeon who is familiar with patient selection criteria and surgical technique would have the highest neck fracture rate," it said.

So problems were being picked up in the premarket clinical study - despite some insisting that these studies are too small for this purpose. Surgeons experienced in the resurfacing technique should not have a fracture rate of more than $1 \%$ a year. ${ }^{12}$ Yet according to a June 2008 document from the French health agency Haute Autorité de Santé, this two year follow-up study had a $4.9 \%$ fracture rate in the ASR resurfacing arm. And the two year survival of the implant was $95.9 \%$ (95\% confidence interval $93.5 \%$ to $99.9 \%$ ) when only $25.6 \%$ of people in the group were women - who typically fared worse with the prosthesis. ${ }^{9}$ The French agency concluded in 2008 that given the data and the alternatives it would not fund the ASR resurfacing. But it was still being used in the NHS.

DePuy's response to the FDA questions shows its close relationship with the surgeons it chooses to participate in its regulatory studies and the hold it believes it has over them. The company assigned the list of questions to one of its marketing representatives with experience in regulatory affairs. It asked the representative to formulate the answers and ask Mr Nargol to sign the document if needed. In the end the company withdrew its application and the ASR resurfacing was never approved by the FDA.

But this did not stop US surgeons from using it "off label." Rita Redberg, editor of Archives in Internal Medicine and a cardiologist, has studied the US device regulatory system and testified to recent Congressional hearings. 
"Patients have a right to know what the risks and benefits of any procedure are for them. If a device is used off label, it generally means there are not good data to support its use for that indication. That is information that should be discussed in the informed consent process. These discussions are particularly important for an implanted device, which cannot easily be removed," she says.

\section{Similar equivalence-a flawed approach}

Although the FDA's premarketing approval process requiring a clinical study may have protected patients from the widespread uptake of the failing ASR resurfacing prosthesis, the same could not be said about ASR XL, the total hip replacement. This passed through the FDA's 510(k) clearance process via the "similar equivalence" route, whereby companies need only to show that their product is similar to something else on the market. Even a small change in design can have a substantial effect on long term outcome. ${ }^{13}$

Critics say that the similar equivalence route is not nearly stringent enough. ${ }^{14}$ Yet this is how $90 \%$ of devices gain US approval. ${ }^{15}$ Companies say that toughening up the approval process will be bad for patients - they will be denied access to new improved technologies that are available elsewhere. But can this be true in a market saturated with hip prostheses? Isn't there an argument that the bar for market entry should be raised? According to data from the 2010 Australian Joint Registry report, there are more than 1539 stem and acetabular combinations for total hip replacement, but only 72 are commonly used (defined as having been used in more than 400 recorded procedures). ${ }^{16}$

Yet, companies scarcely let a year go by without introducing a "new improved" joint replacement which "offers undreamt of (and unproved) advantages over the older designs."17

The same is true in other fields. Alan Fraser, an interventional cardiologist at Cardiff University, says: "I think any doctor who is treating patients is keen to try to stay up to date and use the most recent advances. And indeed, I think there is a tendency for doctors to want to use whatever the latest new technology is, and perhaps not always to be critical as to whether or not it's really been thoroughly evaluated."

The desire to use something newer, smaller, and shinier might well trump the evidence base. And nearly 20 years ago an editorial in the $B M J$ warned that this "fashion trade" in joint replacements is costing the health service many millions of pounds each year and, even more important, is causing patients unnecessary pain and distress through early failure of unproved implants. ${ }^{17}$ And judging from the recent history of joint failures, it seems not much has changed.

\section{Surgeons and the company}

Surgeons involved in the design of a device can make large sums of money. One of the surgeons involved in the design of the ASR, Thomas Schmalzried, medical director of the Joint Replacement Institute in Los Angeles, received just under $\$ 3 \mathrm{~m}$ (£1.9m; $€ 2.1 \mathrm{~m})$ in royalties during $2009-10$ alone. In the same period, another of the designers, Thomas Vail, University of California San Francisco professor, received just over \$500 000. Figures are not available for the other designers - their respective countries do not have the same legislation about transparency of company payments as the US.

Royalties are legal, as are consultancies, research fees, and stock options. But some companies have been in trouble for providing other kinds of payment.
Four years ago, four of the major orthopaedic companies in the US were fined about $\$ 311 \mathrm{~m}$ for paying doctors to use their products. ${ }^{18}$ And last month, DePuy was ordered by the UK court to pay almost $£ 5 \mathrm{~m}$ for similar unlawful payments in Greece between 1998 and2006, ${ }^{19}$ while Johnson and Johnson was fined $\$ 21.4 \mathrm{~m}$ by the US court for making "improper payments to publicly employed health care providers in Greece, Poland and Romania in order to induce the purchase of medical devices and pharmaceuticals" made by their subsidiaries_including DePuy. ${ }^{20}$

Charles Rosen, professor of orthopaedic surgery at University of California, Irvine, School of Medicine, says companies try to find a relationship to keep you using that product. "It could be in the form of maybe having you as a consultant with the company for a certain amount per year and then you feel obligated to continue using that product. Or have you lead courses in how to use that drug or that device and reimburse you for that and tie you up to become an advocate as well as a user of that product," he says.

At the time of the launch of the ASR, DePuy was behind in the sales stakes and it would have to turn to its design surgeons. The ASR's design surgeons located in several different countries acted as key opinion leaders, promoting the new device. They led educational programmes, published papers in journals, spoke at company dinners, and presented at conferences promoting the ASR.

\section{Marketing campaign}

A successful marketing campaign would be crucial to persuading surgeons to change from the BHR to the ASR resurfacing in Europe. Among its many strategies, DePuy ran simulator tests on its prosthesis and its competitor. The pictures appeared to show that the ASR produced less metal wear debris than the BHR - the ASR fluid was clear whereas the BHR was sitting in a dark metallic stained fluid. An accompanying journal article indicated that the ASR fluid had been changed and the pictures of the two devices had been taken at different time points. ${ }^{21} 22$ Yet these pictures were used by sales representatives for marketing purposes divorced from the accompanying article and might have been misleading. ${ }^{23}$ When we put this to DePuy, it said that it would not respond to "speculation."

But in the absence of publicly available data and no independent assessment of study summaries in Europe, manufacturers are able to interpret and promote their studies as they wish. This is in stark contrast to the US, where devices can only be marketed for a clinical claim that is included in labelling that has been reviewed by the FDA. Even the MHRA does not routinely collect any premarket clinical data. This means that clinical claims are difficult to verify.

Tony Nargol was one of the surgeons who was persuaded to change from the Birmingham hip after being shown the pictures by DePuy in 2004. As internal emails show, the company targeted him because he was known to be a big user of the BHR.

"They said the ASR would last considerably longer than a Birmingham [Hip Resurfacing]," Mr Nargol said. He described the simulator test he was shown. "After a while the BHR went all black. It looked like metal had come off the bearing and it looked abnormal. And there's a clear difference between the two and it was very persuasive. And I know a lot of surgeons round the world were very persuaded by this." 


\section{Device failure or surgical technique?}

A few years later, Mr Nargol started to notice problems with the ASR. In early 2007, some of his patients reported groin pain and difficulty walking. He got a shock when he opened them up to revise their prostheses. "The soft tissues and muscles around the hip were destroyed." He noticed a pus-like fluid coming from the capsule. Initially he put it down to infection. But cultures were negative. "And then we went on to find cases where the bone was starting to get destroyed as well," Mr Nargol said.

Other surgeons also mentioned problems with the device. But according to Mr Nargol, some of those with ties to DePuy declined to report what they were seeing and simply stopped using the device.

He raised his concerns with the company, and asked whether anyone else was having problems. As internal emails show, company managers hoped to pass this off as a failure of surgical technique-even though he was an experienced resurfacing surgeon. "I' $m$ sure that the complications that Tony has experienced are wholly related to interoperative surgical technique compromises and I'm sure if managed effectively we can ensure that the published presented data from North Tees draws this conclusion and more critically clearly illustrates that it is not a device related complication," an email said.

Professor Graves says this response is not wholly surprising. "There's a natural tendency for companies [to think] it's probably factors other than a device, because they have invested a lot of time in it ... It does take some time on occasions to convince a company that there may be problems with the device."

The high revision rate of the ASR should not have come as a surprise to the company or to the regulators. In 2005, Mr McMinn-designer of the Birmingham Hip

Resurfacing — participated in a debate in Helsinki pitching the prosthesis he had created against the ASR. While Mr McMinn's arguments primarily focused on his prosthesis, he described in detail what he perceived to be the ASR's design flaws that would later lead to its demise. ${ }^{11-29}$

He criticised the shallowness and the rim on the inside of the cup and the manufacturing processes used, all of which, he said, could lead to increased wear. The design changes, he said, would mean the prosthesis would be less forgiving of surgeon technique-something which, some argue, should be factored into the design of a successful device. ${ }^{30}$

Mr McMinn says DePuy were "certainly aware of this lecture" and the "president wrote to me in a non-friendly tone 'advising' me to remove this talk from my website." He declined to remove it and it's been there ever since. DePuy chose not to comment on this allegation.

The company was also aware of raised blood levels of metal ions. At a conference in Dallas in 2007 one of DePuy's engineers gave a presentation, seen by this investigation, of two year follow-up data that showed $30 \%$ of women and $7.5 \%$ of men had markedly raised metal ion concentrations in their blood. Even though the procedures in the study had been performed by the design surgeons-who would be expected to position the device with the most precision - the presentation concluded that surgical technique was to blame.

The following year, in 2008, Mr Langton, who had been analysing both the ASR and the BHR, gave a presentation at the British Orthopaedic Association conference in Liverpool describing the problems caused by the shallowness of the ASR cup. This, he said, was leading to increased wear as the edge of the cup rubbed against the head. DePuy representatives were at the meeting.

\section{Registry data also dismissed}

By 2007, individual surgeons were not the only people noticing problems. The Australian National Joint Replacement Registry reported that the ASR had a high revision rate. The registry was set up to spot "outliers"- prostheses that have twice the rate of revision of others in their class. All hip prostheses fail in some patients, but it is expected that the rate will be about $1 \%$ a year. The Australian data showed a 5.16\% (95\% confidence interval $3.50 \%$ to $7.56 \%$ ) revision rate at two years. ${ }^{31}$

The registry uses revision as the primary outcome to identify implants that aren't performing as well as they should. Of course, it's only one measure of how well a joint performs, but according to Professor Graves, it's an "unambiguous end point—nobody can argue about [it]."

But that's precisely what DePuy did. According to Professor Graves, when the registry first notified DePuy about the high revision rate, the company released a safety warning to surgeons saying that positioning was important.

Over the next three years, DePuy used a range of techniques and arguments to try to assuage fears arising from the evidence generated repeatedly by the Australian registry and surgeons themselves. ${ }^{16-32}$

According to a presentation Professor Graves gave at a meeting in Glasgow, the Australian joint registry warned the Australian regulators and DePuy 17 times about problems with the ASR between 2007 and 2009.

But, according to internal company documents, concerns were explained away and sales representatives were instructed to keep on marketing the product. To counter the Australian registry's findings, internal documents show that DePuy sent out a "white paper" by one of the ASR design surgeons, Professor Vail, explaining how to interpret the Australian data. It said that the Australian data did not account for the surgeons' learning curve with resurfacing. The Australian rates were almost double those of the "international surgeon design team at two years," it added. In order to "set the record straight" the sales representatives were told to tell surgeons about a paper detailing the American experience with the BHR, which reported an adverse event rate of $4.9 \%$, which they claimed was higher than for the ASR..$^{33}$ Their marketing team also quibbled with the exact definition of the term "revision" used by the Australian registry.

Surgeons carrying out a lot of operations had the same failure rates as those doing only a few, Professor Graves says. So their findings totally contradicted DePuy's assertion that surgical experience and patient selection were to blame. "We were quite strong in our conclusion," says Professor Graves, "We thought it was the device."

Meanwhile the North Tees team-including Mr Nargol and Mr Langton-were keeping DePuy updated about the problems they were finding and their data, as internal emails show. At a meeting in Norwich in 2008, they gave a presentation reporting the cases of 10 women with soft tissue reactions who had significantly increased metal ion concentrations in their blood and high joint fluid metal ions. Representatives of both DePuy and the MHRA attended.

Before presenting the data, Mr Langton had sought advice from a senior surgeon-who, according to internal emails, had instructed DePuy on promoting the ASR. He advised $\mathrm{Mr}$ 
Langton to keep quiet. "He told me, "you have great data which will allow you to travel the world. But my advice would be not to present it at the Hip Society. I would go to DePuy and suggest a consultancy role with them. You can earn a lot of money just for doing nothing. I have done this a couple of times in the past with previous research,'” Mr Langton said he didn't take the advice.

\section{Targeting women}

One paper-published in mid-2008 and seen by DePuy before submission - showed that several of the ASR patients had raised chromium and cobalt concentrations in their blood. In some patients, these concentrations were 100 times greater than normal physiological values. ${ }^{34}$

It was also clear from these data that patients implanted with smaller ASRs, used mainly in women, were more likely to develop higher metal ion concentrations-as DePuy's own presentation in Dallas the year before had shown.

Yet this was the group of patients targeted by DePuy in an "advertorial" in the Daily Telegraph on 21 February 2008. Featuring quotes from the UK design surgeon Andrew Cobb and a young woman, Penny Brown, who said her life had been changed by the ASR, the advertorial "aimed to educate patients on their treatment options and demonstrate the unique advantages that the DePuy ASR can provide to the right patients." Unlike prescription drugs, there is no European legislation preventing direct to consumer advertising of devices.

According to John Nolan, orthopaedic surgeon at Norfolk and Norwich Hospital, patients were keen to have resurfacing. They would see adverts for it on the internet. "The emergence of resurfacing hip surgery coincided with the increased use of the internet to advertise hip replacement surgery on websites that were not peer reviewed. As a result, patients would request resurfacing surgery when it was not appropriate. I believe the surgeon has a professional responsibility to advise the patient accordingly and to decline the procedure when the correct indications are not present," he said.

And rather than advise surgeons not to use the ASR in women-DePuy merely instructed surgeons to be careful how they put the cup part of the implant in — again refusing to believe that it might be the device that was giving rise to the large increases in chromium and cobalt concentrations. $\mathrm{Mr}$ Langton was even told by a DePuy sales representative that good sources had told them that an illegal chromium ship unloaded its cargo in the river Tees a couple of years earlier and that was the reason for the raised chromium and cobalt levels he was finding in patients' blood. DePuy declined to comment on this allegation.

But it was the threat of losing a valued surgeon to their rival that made DePuy really start to take note. Panic started to set in in early 2009. In an email written in capitals, a local sales representative wrote: "Tony Nargol has said he will no longer use ASR at Hartlepool and instead will use BHR.” The company had calculated the value of his custom-over a quarter of a million pounds in 2008. The representative said they would "work as closely as possible with Tony and to move him to Silent [another DePuy implant] as soon as possible to brickwall the account against competitors."

Later that year, DePuy was still in denial about the extent of the problems and was providing a counter argument to any concerning data. An internal email from March 2009 reported on outreach to surgeons. "All major XL users have been seen over recent weeks and are happy with their results."

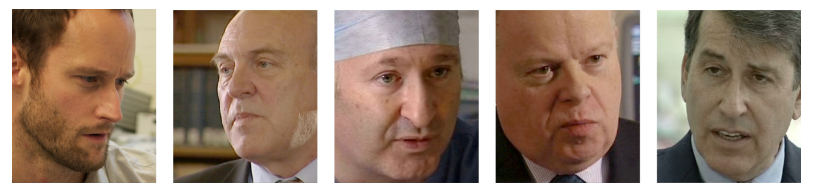

L to R: David Langton, Stephen Graves, Tony Nargol, Alan Fraser and Charles Rosen

\section{Reporting adverse events}

But not all surgeons were happy, and their revision rates were far higher than they ought to be. Shouldn't the regulators have stepped in to remove the product from the market and stop those who were purportedly happy to continue to implant the ASR?

In the UK, the onus is on manufacturers, doctors, and patients to report problems directly to the MHRA — and the MHRA itself has been critical of the deficiencies in postmarket clinical follow-up. ${ }^{35}$ According to the Association of British Healthcare Industries, manufacturers capture and analyse information from a variety of sources - clinical follow-up, registries, published and unpublished literature, expert meetings, and complaints.

The MHRA told the $B M J$ that it is the "manufacturer's responsibility to monitor the performance of their devices, for as long as they are in use, and to ensure these devices continue to be safe and suitable for clinical use. If in the light of this evaluation, the manufacturer establishes that products should not be used, the manufacturer should take the necessary steps to ensure patient safety."

But, in the case of the ASR, they chose which evidence to believe. And we have no way of knowing if doctors and patients reported adverse events to the regulator or what kind of postmarketing surveillance was required of the company.

The BMJ and Channel 4 Dispatches filed a Freedom of Information request asking the MHRA for reports of adverse reactions to the ASR. This was declined under medical directive legislation that keeps all device regulatory affairs confidential. Nor could we access documents that would show what kinds of discussions the MHRA or the notified body were having with the company.

\section{Role of MHRA}

They knew that there were concerns about the risks of metal debris from wear of orthopaedic metal implants. In March 2006, an expert advisory group at the MHRA discussed the issue. "There is evidence to suggest that some metal on metal hip replacements may be associated with increased DNA-changes, which might result in genotoxicity in patients. ${ }^{, 36}$ But it was not known whether there were any clinical implications of the findings. "The benefits of such implants are real. Whereas the discussed risk is theoretical and unquantifiable, but definitely low," it said.

But the agency knew it was a sensitive topic. Before the paper was presented, the chairman stressed the importance of confidentiality, adding that "anyone who felt they were unable to keep this matter completely confidential was asked to leave the room."

Despite the raft of data being published in both the medical literature and as formal registry reports over a number of years, the ASR was left on the market. No one from the MHRA contacted Mr Nargol and Mr Langton to follow-up their data despite the MHRA having a group specifically to look at metal on metal concerns for several years.

At the end of 2009, DePuy voluntarily recalled the ASR in Australia. But, according to Professor Graves, their registry 
reports had influenced the practice of the Australian surgeons and the number implanted had already dropped.

But it remained on the market in the rest of the world. Confused by the apparent inaction by the MHRA, in April 2010 a team from University Hospital of North Tees directly approached the agency to force it to acknowledge the problems associated with the ASR. By this time they were seeing a $15 \%$ revision rate at five years and almost all patients had tissue damage to some extent.

Mr Nargol told the investigation that the MHRA officials stopped the team's presentation halfway through, saying they believed the team and asking what they wanted. But when $\mathrm{Mr}$ Nargol and Mr Langton said the ASR should be banned, the MHRA officials said they couldn't do that as they would be sued. Instead, the MHRA sent out a medical device alert warning about all metal on metal hip implants. However, a spokesperson for the MHRA said that "the MHRA would never be influenced by the threat or possibility of legal challenge in not taking regulatory action it thought to be appropriate."

Shortly after, UK National Joint Registry (NJR) saw a rapid rise in the number of revisions. Up until this point there had been a rate of $7.5 \%$. But this increased and they notified the MHRA. Internal company documents show that DePuy had decided to phase out the ASR globally by the end of 2010 for "commercial performance" reasons. In a statement to the investigationDePuy said that this decision "was not related to any concerns about product safety."

"At the time of the decision, data available to DePuy indicated that the revision rate of the ASR Hip System was similar to that reported for other large diameter metal on metal monoblock and resurfacing hip devices," the company said. "Because the decision was based on business factors, not safety concerns, the timing to discontinue sales differed from country to country."

\section{Recall of the ASR}

But in the end, DePuy "voluntarily recalled" the ASR in August 2010, saying the recall was due to unpublished NJR data showing a $12 \%$ revision rate for resurfacing at five years and an ASR XL revision rate of $13 \%$. "Early revision of poorly performing hip replacements that generate metal debris should give a better revision outcome," it added on the field safety notice - the means by which manufacturers alert people that a product is being recalled.

But revision of a destroyed joint is not straightforward. Not only are patients put at anaesthetic risk once again, the revisions have a higher risk of failure. ${ }^{37}$

And although DePuy state that it is "committed to addressing reasonable and customary costs of testing and treatment" for patients who might need revision after the recall of ASR,

"including revision surgery if necessary," there is a cost to the NHS - in some centres primary hip procedures are being put back to accommodate urgent revisions.

But the delay in the recall might serve as a lesson to other companies. Not only will DePuy have to pay for the cost of revision in the NHS, there is global litigation that, if successful, may cost the company many billions of dollars. The last major litigation against a hip manufacturer was against Sulzer in 2002, which resulted in a roughly $\$ 1$ bn payout and a major net loss that year for the company. ${ }^{38}$

But even while DePuy was offering to pay revision costs, it again used the opportunity to promote its products. An internal presentation the day before the recall went out-seen by the $B M J$ and Channel 4 Dispatches — said that since the ASR system was no longer available, none of the components should be used for revision. However, it said that "DePuy offers a full line of both revision and primary acetabular and femoral implants and instruments to meet individual patient needs." For revision of both ASR resurfacing and ASR it recommends a total hip replacement. "DePuy option: Pinnacle," it said-including the cobalt chrome metal implant. And in a briefing to the sales force it said the "Pinnacle is an alternative for the majority of patients."

According to Mr Nolan, this probably wasn't the wisest thing to do. "I don't think it is advisable, in the presence of an adverse soft tissue reaction to a cobalt chrome implant, to revise the hip replacement by using another implant made of cobalt chrome. I feel strongly that all cobalt chrome should be removed from the affected joint," he said.

But a much more widespread problem may be looming involving a range of other makes and models. And once again it illustrates the delicate trade-off between innovation and safety. Like resurfacing, the use of large head metal on metal total hip implants have followed another surgical trend. Heads have got larger to make them less likely to dislocate. But with this comes associated corrosion problems where the head meets the stem. "Some cemented, stemmed, metal on metal implants have shown marked corrosion of the stem and some large diameter head, stemmed implants have shown corrosion at the taper junction of the head/stem," Mr Nolan says.

A two year follow-up study in 144 patients published at the beginning of May this year shows an incremental increase in metal ion levels over the study period in a range of large head metal on metal implants made by manufacturers such as Zimmer, Biomet, DePuy, and Smith and Nephew. ${ }^{39}$ A letter from the British Orthopaedics Association sent out to members at the end of March says the use of large diameter metal on metal bearings in primary total hip replacement should be "carefully considered and possibly avoided." Data now show a higher than expected early failure rate, it said. "These range from $21 \%$ revision rate at 4 years (potentially rising to $35 \%$ if all currently known painful implants progress to revision) to $49 \%$ at 6 years for the ASR XL device. Other devices have a revision or impending revision rate of $12-15 \%$ at 5 years," it added.

And there continues to be debate within the orthopaedic community about what constitutes a large head—one or two centres are seeing problems that others are not. As Mr Langton asked in a presentation to the British Hip Society this year: "Why is the first response not to suspend the implantation [of a device] when legitimate concerns are raised?"

\section{Lack of regulator power}

The story of the ASR shows the power that companies have in deciding the fate of their devices, their hold over surgeons, and the lack of regulatory power in Europe.

The failure of the $3 \mathrm{M}$ hip over 12 years ago prompted calls for a device regulatory system analogous to that set up for drugs, involving clinical trials, a licensing process, and postmarketing surveillance. Some new products will always have rare and unwanted consequences-it's an inevitable consequence of innovation. The regulatory imperative is to ensure that these are limited in scale and picked up early. A good regulatory system will benefit everybody by ensuring patients are not exposed unnecessarily to risk and that manufacturers and others are not exposed to undue liabilities.

But will we learn from the story of the ASR and large head metal on metal prostheses? "I think we have to rethink the whole 
system of how devices come onto the market and whether we should be doing things a bit differently from what we are now," Professor Graves says.

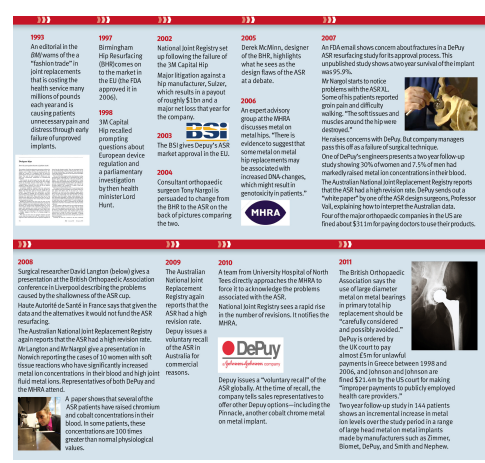

Click to enlarge the timeline

Competing interests: The author has completed the unified competing interest form at www.icmje.org/coi_disclosure.pdf (available on request from her) and declares no support from any organisation for the submitted work; no financial relationships with any organisation that might have an interest in the submitted work in the previous three years; and no other relationships or activities that could appear to have influenced the submitted work.

Provenance and peer review: Commissioned; externally peer reviewed.

FDA. Concerns about metal-on-metal hip implant systems. 2011. Access link here.

2 Muirhead-Allwood SK. Lessons of a hip failure. BMJ 1998;316:644.

3 MHRA. Minutes of the committee on the safety of devices meeting 19 July 2001. Access link here.

4 British Orthopeadic Association. Large diameter metal on metal bearing total hip replacements. 2011. Access link here.

5 Schmalzried TP, Shepherd EF, Dorey FJ, Jackson WO, dela Rosa M, Fa'vae F, et al. The John Charnley Award. Wear is a function of use, not time. Clin Orthop Relat Res 2000;381:36-46.

6 Smith SL, Dowson D, Goldsmith AA. The effect of femoral head diameter upon lubrication and wear of metal-on-metal total hip replacements. Proc Inst Mech Eng $[\mathrm{H}]$ 2001;215:161-70.

7 Smith SL, Dowson D, Goldsmith AAJ. The effect of diametral clearances, motion and loading cycles upon lubrication of metal-on-metal hip replacements. Proc Inst Mech Eng [C] 2001;215:1-5.

8 Cohen D, Billingsley M. Europeans are left to their own devices. BMJ 2011;342:d2748.

9 Haute Authorite de Sante. Commision d'evaluation des produits et prestations, 24 Jun 2008. Access link here.

10 Langton DJ, Jameson SS, Joyce TJ, Hallab NJ, Natu S, Nargol AV. Early failure of metal-on-metal bearings in hip resurfacing and large-diameter total hip replacement: a consequence of excess wear. J Bone Joint Surg Br 2010;92:38-46

11 Kamali A, Hussain A, Li C, Pamu J, Daniel J, Ziaee H, et al. Tribiological performance of various $\mathrm{CoCr}$ microstructures in metal-on-metal bearings: the development of a more physiological protocol in vitro. J Bone Joint Surg Br 2010;92:717-25.

12 Shimmin AJ, Back D. Femoral neck fractures following Birmingham hip resurfacing: a national review of 50 cases. J Bone Joint Surg Br 2005;87:463-4.

13 Learmonth I. The operation of the century: total hip replacement. Lancet 2007;370:1508-19.

14 Zuckerman DM, Brown P, Nissen SE. Medical device recalls and the FDA approval process. Arch Intern Med 2011; Feb 14 [epub ahead of print].

15 PricewaterhouseCoopers. Medical technology innovation scorecard. 2011. Access link here.

16 Australian Orthopaedic Association. National Joint Replacement Registry, annual report 2010. AOA, 2010.
17 Bulstrode CJ, Murray DW, Carr AJ, Pynsent PB, Carter SR. Designer hips. BMJ. 1993;306:732-3.

18 Hopkins Tanne J. US makers of joint replacements are fined for paying surgeons to use their devices. BMJ 2007;335: 1065

19 Serious Fraud Office. DePuy International Limited ordered to pay $£ 4.829$ million in Civil Recovery Order. Access link here.

20 US Department of Justice. Johnson \& Johnson agrees to pay $\$ 21.4$ million criminal penalty to resolve foreign corrupt practices act and oil for food investigations. 2011. Access link here.

21 Dowson D, Hardaker C, Flett M, Isacc GH. Hip joint simulator study of the performance of metal-on-metal joints. Part I: the role of materials. J Arthroplasty 2004;19 (suppl 3).

22 Dowson D, Hardaker C, Flett M, Isacc GH. Hip joint simulator study of the performance of metal-on-metal joints. Part II:Design. J Arthroplasty 2004;19 (suppl 3).

23 Finsbury Orthopaedics. ASR marketing and science. Bulletin No 58. 2006. Access link here.

24 De Haan R, Pattyn C, Gill HS, Murray DW, Campbell PA, De Smet K. Correlation between inclination of the acetabular component and metal ion levels in metal-on-metal hip resurfacing replacement. J Bone Joint Surg Br 2008;90:1291-7.

25 Langton DJ, Sprowson AP, Joyce TJ, Reed M, Carluke I, Partington P, et al. Blood metal ion concentrations after hip resurfacing arthroplasty: a comparative study of articular surface replacement and Birmingham Hip Resurfacing arthroplasties. J Bone Joint Surg Br 2009;91:1287-95.

26 Morlock MM, Bishop N, Zustin J, Hahn M, Rüther W, Amling M. Modes of implant failure after hip resurfacing: morphological and wear analysis of 267 retrieval specimens. J Bone Joint Surg Am 2008;90(suppl 3):89-95.

27 Lee RK, Essner A, Longaray J, Wang A. Metal-on-metal bearings: the problem is edge-loading wear. Surg Technol Int 2010;20:303-8.

28 Kinbrum A, Unsworth A. The wear of high-carbon metal-on-metal bearings after different heat treatments. Proc Inst Mech Eng H 2008;222:887-95.

29 Langton DJ, Joyce TJ, Mangat N, Lord J, Van Orsouw M, Smet KD, et al. Reducing metal ion release following hip resurfacing arthroplasty. Orthop Clin North Am 2011:42:169-80.

30 McMinn Centre. Northern lights debate ASR vs BSR. Access link here.

31 Australian Orthopaedic Association. National Joint Replacement Registry, annual report 2007. AOA, 2007.

32 Australian Orthopaedic Association, National Joint Replacement Registry, annual report 2008. AOA, 2008.

33 Della Valle CJ, Nunley R, Raterman S, Barrack RL. Early American experience with hip resurfacing following FDA approval. Clin Orthop 2009;467:72-8.

34 EU must tackle clinical trials shortfall. Clinica 2010 Jul 26. Access link here.

35 Langton DJ, Jameson SS, Joyce TJ, Webb J, Nargol AV. The effect of component size and orientation on the concentration of metal ions after resurfacing arthroplasty of the hip. J Bone Joint Surg Br 2008;90:1143-51.

36 MHRA. Minutes of the Committee on the Safety of Devices Meeting, 23 March 2006.

37 Grammatopolous G, Pandit H, Kwon YM, Gundle R, McLardy-Smith P, Beard DJ, et al. Hip resurfacings revised for inflammatory pseudotumour have a poor outcome. J Bone Joint Surg Br 2009;91:1019-24.

38 Sulzer Medica. Sales growth of 5 percent-substantial group loss due to US litigation. PR Newswire, 2002. Access link here.

39 Lavigne M, Belzile EL, Roy A, Morin F, Amzica T, Vendittoli P-A. Comparison of whole-blood metal ion levels in four types of metal-on-metal large diameter femoral head total hip arthroplasty: the potential influence of the adapter sleeve. J Bone Joint Surg Am 2011:93:128-36.

Cite this as: BMJ 2011;342:d2905

\section{Related links \\ BMJ Open}

- Medical-device recalls in the UK and the device-regulation process: retrospective review of safety notices and alerts

\section{bmj.com/archive}

- Read more BMJ articles on medical devices (c) BMJ Publishing Group Ltd 2011 